\title{
Current Cytology Practices in Korea: A Nationwide Survey by the Korean Society for Cytopathology
}

Eun Ji Oh ${ }^{1}$. Chan Kwon Jung ${ }^{1,2}$ Dong-Hoon $\mathrm{Kim}^{3}$ • Han Kyeom Kim ${ }^{4}$ Wan Seop Kim ${ }^{5}$. So-Young Jin ${ }^{6}$ Hye Kyoung Yoon ${ }^{7}$. The Fellowship Council and Committee of Quality Improvement of the Korean Society for Cytopathology

${ }^{1}$ Department of Hospital Pathology, ${ }^{2}$ Cancer Research Institute, College of Medicine, The Catholic University of Korea, Seoul; ${ }^{3}$ Department of Pathology, Kangbuk Samsung Hospital, Sungkyunkwan University School of Medicine, Seoul; ; ${ }^{4}$ Department of Pathology, Korea University Guro Hospital, Korea University College of Medicine, Seoul; ; 5 Department of Pathology, Konkuk University School of Medicine, Seoul; ${ }^{6}$ Department of Pathology, Soonchunhyang University Seoul Hospital, Soonchunhyang University College of Medicine, Seoul; ${ }^{7}$ Department of Pathology, Inje University Busan Paik Hospital, Inje University College of Medicine, Busan, Korea

Received: July 4, 2017

Revised: August 7, 2017

Accepted: August 10, 2017

Corresponding Author

Chan Kwon Jung, MD, PhD

Department of Hospital Pathology, Seoul St. Mary's

Hospital, College of Medicine, The Catholic

University of Korea, 222 Banpo-daero, Seocho-gu,

Seoul 06591, Korea

Tel: +82-2-2258-1622

Fax: +82-2-2258-1627

E-mail: ckjung@catholic.ac.kr
Background: Limited data are available on the current status of cytology practices in Korea. This nationwide study presents Korean cytology statistics from 2015. Methods: A nationwide survey was conducted in 2016 as a part of the mandatory quality-control program by the Korean Society for Cytopathology. The questionnaire was sent to 208 medical institutions performing cytopathologic examinations in Korea. Individual institutions were asked to submit their annual cytology statistical reports and gynecologic cytology-histology correlation data for 2015. Results: Responses were obtained from 206 medical institutions including 83 university hospitals, 87 general hospitals, and 36 commercial laboratories. A total of 8,284,952 cytologic examinations were performed in 2015 , primarily in commercial laboratories (74.9\%). The most common cytology specimens were gynecologic samples (81.3\%). Conventional smears and liquid-based cytology were performed in 6,190,526 (74.7\%) and 2,094,426 (25.3\%) cases, respectively. The overall diagnostic concordance rate between cytologic and histologic diagnoses of uterine cervical samples was $70.5 \%$. Discordant cases were classified into three categories: category A (minimal clinical impact, 17.4\%), category B (moderate clinical impact, 10.2\%), and category C (major clinical impact, $1.9 \%$ ). The ratio of atypical squamous cells of undetermined significance to squamous intraepithelial lesion was 1.6 in university hospitals, 2.9 in general hospitals, and 4.9 in commercial laboratories. Conclusions: This survey reveals the current status and trend of cytology practices in Korea. The results of this study can serve as basic data for the establishment of nationwide cytopathology policies and quality improvement guidelines in Korean medical institutions.

Key Words: Cytology; Statistics; Surveys; Quality; Accuracy
The number of cytology cases has been increasing over time in Korea. ${ }^{1}$ In 1988, the Papanicolaou (Pap) smear was first introduced to screen for cervical cancer during regular health check-ups for Korean industrial workers and their family members. ${ }^{2}$ The National Cancer Screening Program for stomach, breast and cervical cancer began in 1999. Over time, participation in this program has increased as both the target population and the cancer types included have expanded. ${ }^{2}$ Recent guidelines for cervical cancer screening in Korea recommend that all asymptomatic women over the age of 20 begin cervical cancer screening with a Pap smear or liquid-based cytology (LBC) and continue every 3 years until the age of 74 (if three-consecutive cytologic examinations have been negative within the previous 10 years). ${ }^{3}$

The Korean Society for Cytopathology is committed to improving the quality of cytologic diagnosis and guiding the administration and management of cytology laboratories. The 
Table 1. Assessment of diagnostic accuracy in cervical cytology

\begin{tabular}{|c|c|c|}
\hline Histologic diagnosis & Cytologic diagnosis & Category \\
\hline \multicolumn{3}{|l|}{ Squamous cell } \\
\hline \multirow[t]{6}{*}{ Negative } & Negative & $\mathrm{O}$ \\
\hline & ASCUS & A \\
\hline & ASC-H & B \\
\hline & LSIL & B \\
\hline & HSIL & C \\
\hline & Squamous cell carcinoma & C \\
\hline \multirow[t]{6}{*}{ LSIL } & Negative & $\mathrm{B}$ \\
\hline & ASCUS & A \\
\hline & ASC-H & A \\
\hline & LSIL & 0 \\
\hline & HSIL & B \\
\hline & Squamous cell carcinoma & B \\
\hline \multirow[t]{6}{*}{ HSIL } & Negative & C \\
\hline & ASCUS & B \\
\hline & ASC-H & A \\
\hline & LSIL & $\mathrm{B}$ \\
\hline & HSIL & 0 \\
\hline & Squamous cell carcinoma & A \\
\hline \multirow[t]{6}{*}{ Squamous cell carcinoma } & Negative & C \\
\hline & ASCUS & C \\
\hline & ASC-H & $\mathrm{B}$ \\
\hline & LSIL & $\mathrm{B}$ \\
\hline & $\mathrm{HSIL}$ & A \\
\hline & Squamous cell carcinoma & 0 \\
\hline \multicolumn{3}{|l|}{ Glandular cell } \\
\hline \multirow[t]{5}{*}{ Negative } & Negative & 0 \\
\hline & Atypical glandular cells & A \\
\hline & $\begin{array}{l}\text { Atypical glandular cells favor } \\
\text { neoplastic }\end{array}$ & B \\
\hline & $\begin{array}{l}\text { Endocervical adenocarcinoma } \\
\text { in situ }\end{array}$ & C \\
\hline & Adenocarcinoma & C \\
\hline \multirow[t]{5}{*}{ Adenocarcinoma in situ } & Negative & B \\
\hline & Atypical glandular cells & A \\
\hline & $\begin{array}{l}\text { Atypical glandular cells favor } \\
\text { neoplastic }\end{array}$ & A \\
\hline & $\begin{array}{l}\text { Endocervical adenocarcinoma } \\
\text { in situ }\end{array}$ & O \\
\hline & Adenocarcinoma & A \\
\hline \multirow[t]{5}{*}{ Adenocarcinoma } & Negative & C \\
\hline & Atypical glandular cells & $\mathrm{B}$ \\
\hline & $\begin{array}{l}\text { Atypical glandular cells favor } \\
\text { neoplastic }\end{array}$ & $\mathrm{B}$ \\
\hline & $\begin{array}{l}\text { Endocervical adenocarcinoma } \\
\text { in situ }\end{array}$ & A \\
\hline & Adenocarcinoma & 0 \\
\hline \multicolumn{3}{|l|}{ Other } \\
\hline \multirow[t]{6}{*}{ Other malignant neoplasm } & Negative & C \\
\hline & ASCUS & B \\
\hline & ASC-H & B \\
\hline & LSIL & $\mathrm{B}$ \\
\hline & $\mathrm{HSIL}$ & A \\
\hline & Squamous cell carcinoma & A \\
\hline
\end{tabular}

\begin{tabular}{llc}
\hline Histologic diagnosis & \multicolumn{1}{c}{ Cytologic diagnosis } & Category \\
\hline Atypical glandular cells & $\mathrm{B}$ \\
$\begin{array}{l}\text { Atypical glandular cells favor } \\
\text { neoplastic } \\
\text { Endocervical adenocarcinoma } \\
\text { in situ } \\
\text { Adenocarcinoma }\end{array}$ & $\mathrm{A}$ \\
\hline
\end{tabular}

ASCUS, atypical squamous cells of undetermined significance; ASC-H, atypical squamous cells ca nnot exclude high-grade squamous intraepithelial lesion; LSIL, low-grade squamous intraepithelial lesion; HSIL, highgrade squamous intraepithelial lesion.

Committee for Quality Improvement (QI), founded in 1992, monitors and evaluates cytopathologic outcomes on a regular basis. This committee has generated standard operating procedures and documents for quality assurance/quality control since 1995; this is the same year that the first nationwide survey for quality control in cytopathology was conducted. ${ }^{1}$ Cytology proficiency testing has been performed as a part of QI programs since 1996. Every year since 2003, all cytopathology laboratories have been required to submit the previous year's quality control statistics and participate in two cytology proficiency testing programs as provided by the QI committee. ${ }^{1}$ The QI program has contributed to a reduction in cervical cancer mortality, reducing the odds ratio to 0.36 (95\% confidence interval, 0.31 to 0.43$).^{3}$

In this study, we present nationwide cytology statistics from 2015, including the number of cytology cases, specimen type, case volume by diagnosis, specimen preparation methods, and cytology-histology correlations.

\section{MATERIALS AND METHODS}

The QI Committee of the Korean Society for Cytopathology conducted a nationwide quality control survey in cytopathology from February 2, 2016, to February 22, 2016. The questionnaire was sent to 208 medical institutions performing cytopathologic examinations in Korea in order to gather statistical data on cytology and gynecologic (GYN) cytology-histology correlation results from 2015. Written informed consent was obtained from each institution. This study was approved by the Institutional Review Board of The Catholic University of Korea, Seoul St. Mary's Hospital (KC13SISI0198).

For the purposes of this study, medical institutions were categorized into three groups: university hospitals, general hospitals, and commercial laboratories. All cytology samples were also classified into three groups: GYN, fine needle aspiration (FNA), and non-GYN/non-FNA samples including body fluids, urine, bronchial washing/brushing samples, cerebrospinal fluid, etc. 
The diagnostic concordance between cytologic and corresponding histologic examinations of the uterine cervix was categorized as either concordant (category $\mathrm{O}$ ) or into one of three discordant categories: category A (minimal clinical impact), category B (moderate clinical impact), and category $\mathrm{C}$ (major clinical impact). The criteria for the assessment of diagnostic accuracy are shown in Table 1.

Statistical analysis was performed using GraphPad Prism software ver. 6.05 (GraphPad Software, La Jolla, CA). p-values less than .05 were considered statistically significant. Graphs were generated using GraphPad Prism and Microsoft Excel.

\section{RESULTS}

Responses were obtained from 206 out of 208 medical institutions (99.0\%) including 83 university hospitals, 87 general hospitals, and 36 commercial laboratories.

\section{Statistics of all cytopathology cases in 2015}

The total number of cytopathologic examinations performed in 2015 was $8,284,952$, of which $5,717,336(69.0 \%)$ were performed in commercial laboratories, 1,603,591 (19.4\%) in university hospitals, and 964,025 (11.6\%) in general hospitals (Fig. 1A).

Out of a total of 8,284,952 samples examined, $6,734,465$ $(81.3 \%)$ were classified as GYN, 314,893 (3.8\%) as FNA, and 1,235,594 (14.9\%) as non-GYN/non-FNA (Fig. 1B).

In all, 6,190,526 (74.7\%) cytology samples were prepared for conventional smear (CS) and 2,094,426 (25.3\%) were prepared for LBC. Among the CS samples, $81.2 \%$ were GYN, 3.5\% were FNA, and $15.3 \%$ were non-GYN/non-FNA. Among the LBC samples, $81.5 \%$ were GYN, $4.7 \%$ were FNA, and $13.9 \%$ were non-GYN/non-FNA (Fig. 1C).

\section{Statistics of GYN cytology}

The number of GYN cytology samples was 6,734,465. GYN cytology samples were examined mainly at commercial labora-
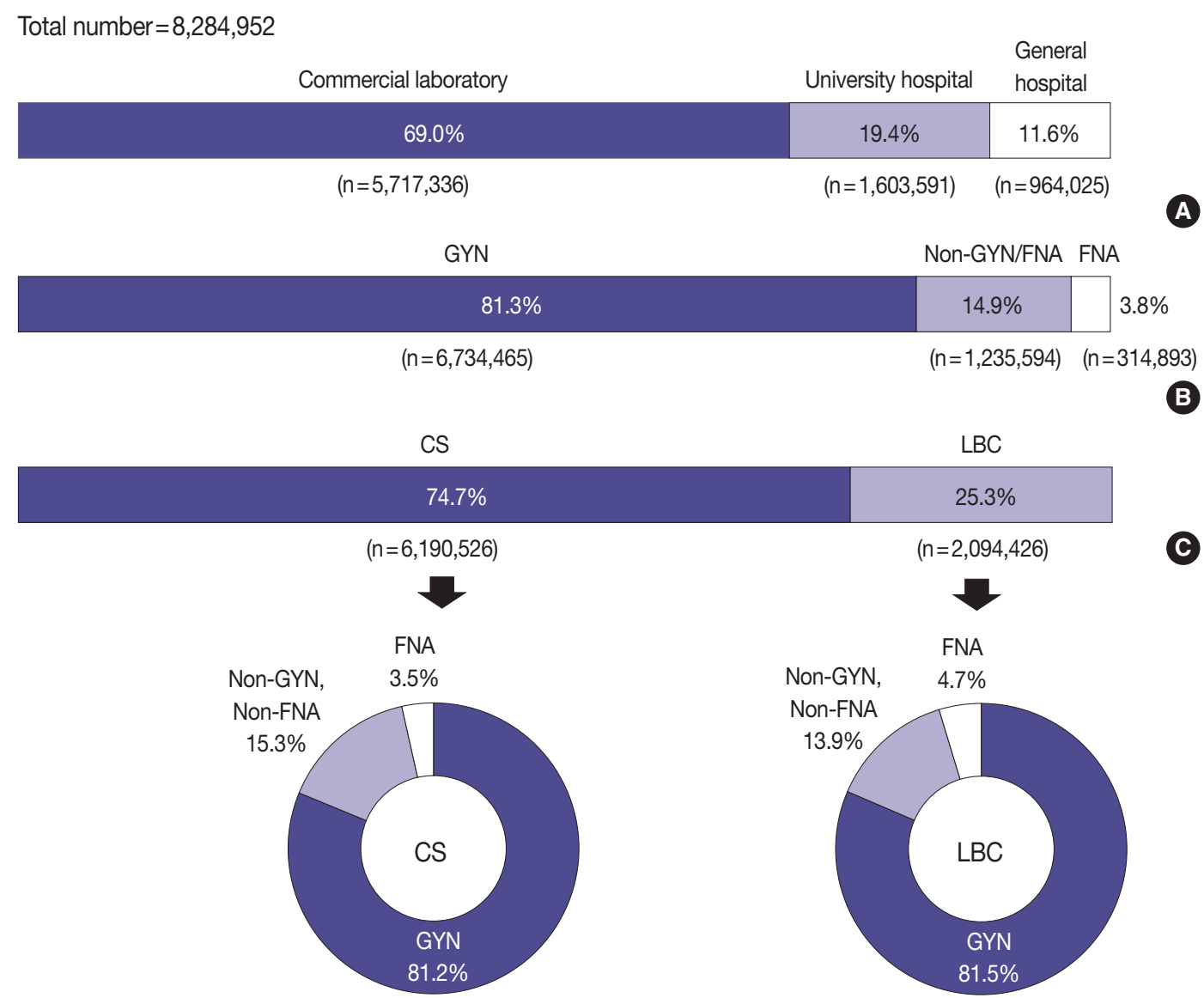

Fig. 1. Number of cytopathology cases in 2015 according to the type of medical institution (A), specimen (B), and preparation method (C). GYN, gynecologic; FNA, fine needle aspiration; CS, conventional smear; LBC, liquid-based cytology. 
tories $(74.9 \%, \mathrm{n}=5,043,280)$ and followed by university hospitals $(13.9 \%, \mathrm{n}=935,590)$ and general hospitals $(11.2 \%, \mathrm{n}=755,595)$ (Fig. 2A).

GYN cytology samples in commercial laboratories and general hospitals were more frequently examined by CS than LBC, whereas university hospitals preferred LBC over CS (Fig. 2B).

\section{Statistics of FNA cytology}

A total of 314,893 FNA cytology samples were examined. Among them, 133,849 (42\%) were examined in commercial laboratories, 125,059 (40\%) in university hospitals, and 55,985 $(18 \%)$ in general hospitals (Fig. 3A).

The most common specimens were thyroid followed by lung (Fig. 3B). FNA Samples in university hospitals showed the highest ratio of LBC to CS followed by general hospitals and commercial laboratories in descending order (Fig. 3C).

\section{Statistics of non-GYN, non-FNA cytology}

A total of 1,235,594 non-GYN/non-FNA cytology samples were examined, consisting of 542,942 (43.9\%) from university hospitals, 540,207 (43.7\%) from commercial laboratories, and 152,445 (12.3\%) from general hospitals (Fig. 4A). The proportion of each specimen type (respiratory, body fluid, urine, cerebrospinal fluid, etc.) is shown in Fig. 4B. The most common type of nonGYN/non-FNA specimen was respiratory cytology, regardless of the type of institution. The ratio of LBC to CS was higher in university and general hospitals than in commercial laboratories (Fig. 4C).

\section{Methods of LBC preparation}

A total of 11 methods for LBC preparation were used: ThinPrep (Hologic, Marlborough, MA, USA), Cell Prep (Biodyne, Seongnam, Korea), SurePath (BD Diagnostics, Sparks, MD, USA), Huro Path (CelltraZone, Seoul, Korea), MonoPrep (MonoGen, Arlington Heights, IL, USA), Prex-Prep, EASY Prep (YD Diagnostics, Yongin, Korea), Cell Scan (Cell \& Tech Bio, Seoul, Korea), CYTOfast (Hospitex Diagnostics, Firenze, Italy), Liqui-PREP (LGM International, Melbourne, FL, USA), and Max-Prep (Fig. 5). The number of medical institutions using each type of LBC preparation method is listed here in descending order: ThinPrep (68), SurePath (44), Cell Prep (17), EASY Prep (9), Huro Path (5), Cell Scan (4), and Prex-Prep (2). Only one institution used a preparation other than the aforementioned methods. The most commonly used LBC method was ThinPrep (39.7\%) followed by Cell Prep (26.3\%) and SurePath (23.7\%); the others methods accounted for less than $5 \%$ of LBC cases. In GYN cytology specimens, ThinPrep (38.8\%) was most commonly used followed by Cell Prep (30.0\%) and SurePath (19.4\%). In non-GYN/nonFNA cytology specimens, SurePath (49.9\%) was most commonly used followed by ThinPrep (44.7\%) and Cell Prep (2.6\%). In

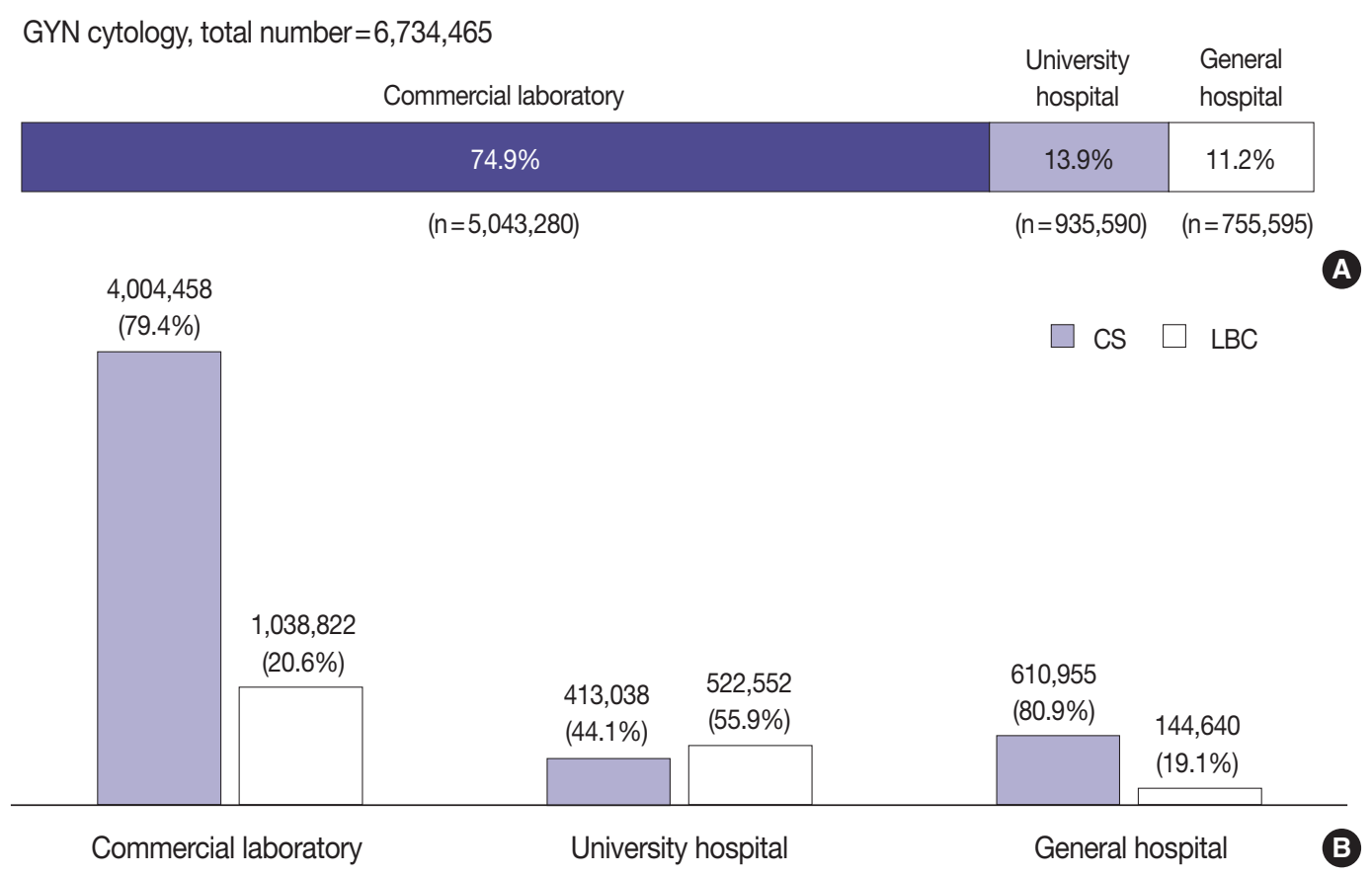

Fig. 2. Number of gynecologic (GYN) cytology cases in 2105 according to the type of medical institution (A) and sample preparation method (B). CS, conventional smear; LBC, liquid-based cytology. 
FNA cytology, total number $=314,893$
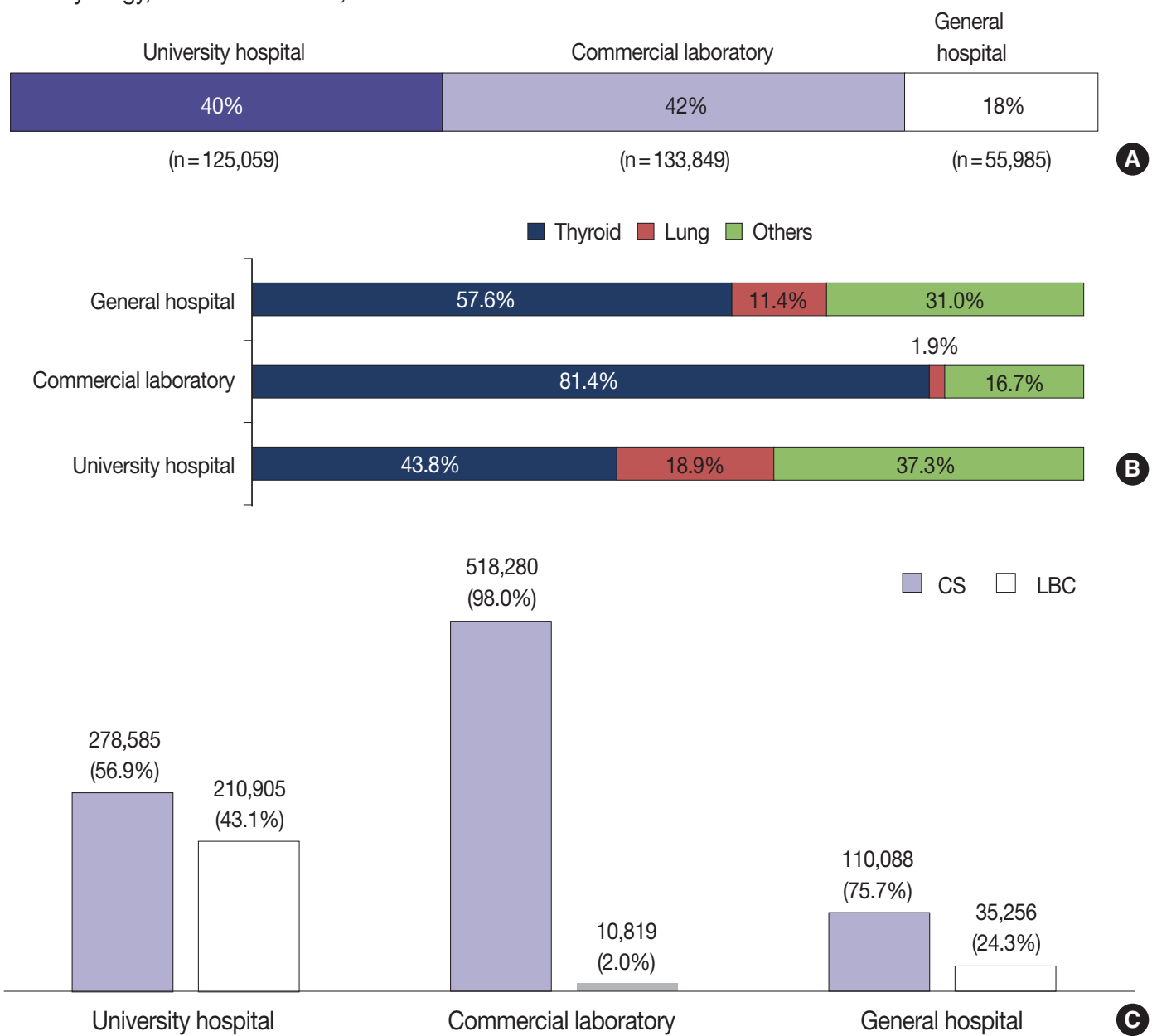

Fig. 3. Number of fine needle aspiration (FNA) cytology cases in 2105 according to the type of medical institution (A), specimen (B), and sample preparation method (C). CS, conventional smear; LBC, liquid-based cytology.

FNA cytology specimens, ThinPrep (45.0\%) was most commonly used followed by SurePath (33.6\%), EASY Prep (12.9\%), and Huro Path (4.5\%).

\section{Prevalence of cytologic diagnoses of the uterine cervix}

Of the GYN cytology samples, 95\% were diagnosed as negative, $3 \%$ as atypical squamous cells of undetermined significance (ASCUS), and $1 \%$ as low-grade squamous intraepithelial lesion (LSIL). In each type of institution, $1 \%$ of samples were considered to be unsatisfactory. The frequencies of unsatisfactory, negative, ASCUS, atypical squamous cells-cannot exclude high-grade squamous intraepithelial lesion, atypical glandular cells (AGC), AGC-favor neoplastic, LSIL, high-grade squamous intraepithelial lesion, adenocarcinoma in situ, squamous cell carcinoma, adenocarcinoma, etc. are shown in Table 2.

The ratio of atypical squamous cells of undetermined significance to squamous intraepithelial lesion (ASCUS:SIL), representing the screening sensitivity, was significantly higher in commercial laboratories $(6.0 \pm 9.2)$ than in university hospitals $(1.9 \pm 2.0)$ and general hospitals $(2.8 \pm 3.0)(\mathrm{p}<.001)$ (Fig. 6).

\section{Diagnostic accuracy of GYN cytology}

Statistical data on diagnostic accuracy were obtained from 77 university hospitals and 54 general hospitals (Fig. 7). In university hospitals, a total of 44,044 GYN cytology cases were compared with matching histologic specimens with the following results: $9.1 \%$ in category $\mathrm{A}, 4.0 \%$ in category $\mathrm{B}, 0.6 \%$ in category $\mathrm{C}$, and $86.3 \%$ in category O. In general hospitals, a total of 3,898 GYN cytology cases were compared with matching histologic specimens with the following results: $17.4 \%$ in category $\mathrm{A}, 10.2 \%$ in category B, $1.9 \%$ in category C, and $69.5 \%$ in category O. Accuracy data from commercial laboratories was not available. 
Table 2. Prevalence of cytologic diagnosis of uterine cervix according to the type of medical institution

\begin{tabular}{lcccc}
\hline Cytology & University hospital & Commercial laboratory & General hospital & Total \\
\hline Unsatisfactory & $5,010(0.5)$ & $30,271(0.7)$ & $5,421(0.7)$ & $40,702(0.6)$ \\
Negative & $872,873(93.6)$ & $4,382,832(94.7)$ & $741,720(95.5)$ & $5,997,425(94.6)$ \\
ASCUS & $29,421(3.2)$ & $171,549(3.7)$ & $20,224(2.6)$ & $221,194(3.5)$ \\
ASC-H & $3,792(0.4)$ & $6,640(0.1)$ & $1,504(0.2)$ & $11,936(0.2)$ \\
LSIL & $13,262(1.4)$ & $28,667(0.6)$ & $5,253(0.7)$ & $47,182(0.7)$ \\
HSIL & $5,243(0.6)$ & $6,010(0.1)$ & $1,833(0.2)$ & $13,086(0.2)$ \\
Squamous cell carcinoma & $890(0.1)$ & $500(<0.1)$ & $246(<0.1)$ & $1,636(<0.1)$ \\
AGC & $1,055(0.1)$ & $2,350(0.1)$ & $507(0.1)$ & $3,912(0.1)$ \\
AGC, favor neoplastic & $195(<0.1)$ & $292(<0.1)$ & $74(<0.1)$ & $561(<0.1)$ \\
Adenocarcinoma in situ & $51(<0.1)$ & $4(<0.1)$ & $19(<0.1)$ & $74(<0.1)$ \\
Adenocarcinoma & $348(<0.1)$ & $65(<0.1)$ & $64(<0.1)$ & $13(<0.1)$ \\
Others & $56(<0.1)$ & $628(<0.1)$ & $477(<0.1)$ & $697(<0.1)$ \\
Total & $932,196(100)$ & $4,629,808(100)$ & $776,878(100)$ & $6,338,882(100)$ \\
\hline
\end{tabular}

Values are presented as number (\%).

ASCUS, atypical squamous cells of undetermined significance; ASC-H, atypical squamous cells cannot exclude high-grade squamous intraepithelial lesion; LSIL, low-grade squamous intraepithelial lesion; HSIL, high-grade squamous intraepithelial lesion; AGC, atypical glandular cells.

Non-GYN, non-FNA cytology, total number $=1,235,594$

\begin{tabular}{|cc|c|} 
University hospital & Commercial laboratory & $\begin{array}{c}\text { General } \\
\text { hospital }\end{array}$ \\
\hline $43.9 \%$ & $43.7 \%$ & $12.3 \%$ \\
\hline$(n=542,942)$ & $(n=540,207)$ & $(n=152,445)$ A
\end{tabular}

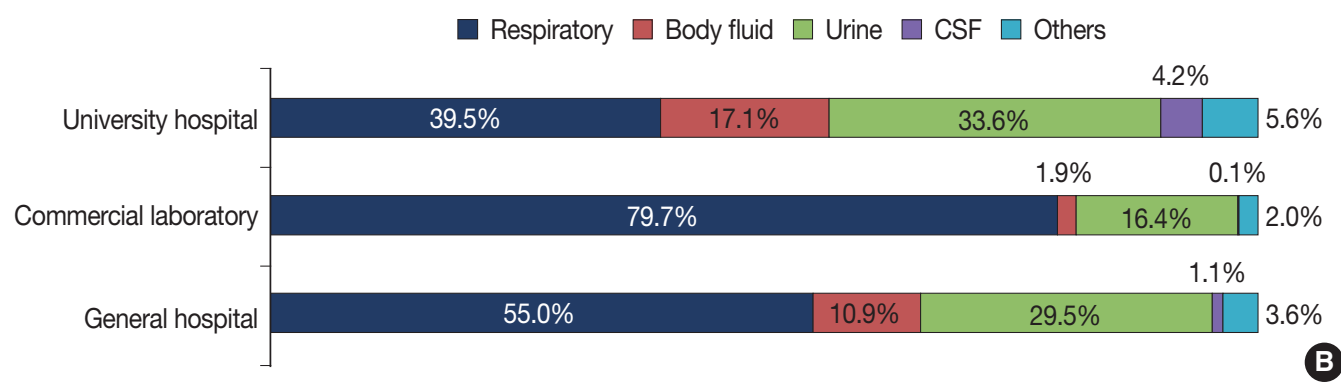

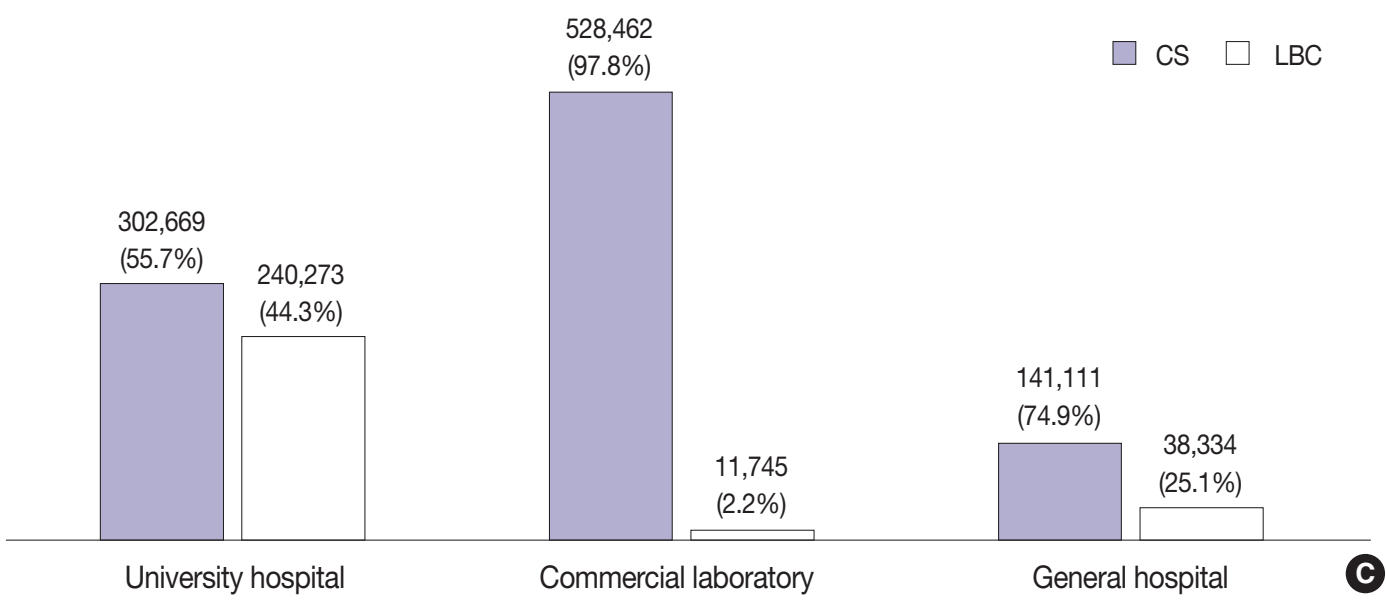

Fig. 4. Number of non-gynecologic (GYN), non-fine needle aspiration (FNA) cytology cases in 2105 according to the type of medical institution (A), specimen (B), and sample preparation method (C). CSF, cerebrospinal fluid; CS, conventional smear; LBC, liquid-based cytology. 
Liquid-based cytology, total number $=2,034,563$

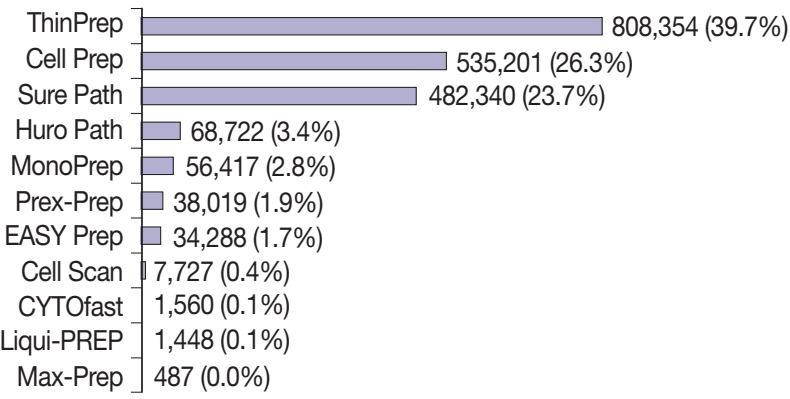

Fig. 5. Usage of liquid-based cytology in 2015 according to number of institutions, number of specimens, and type of specimen.

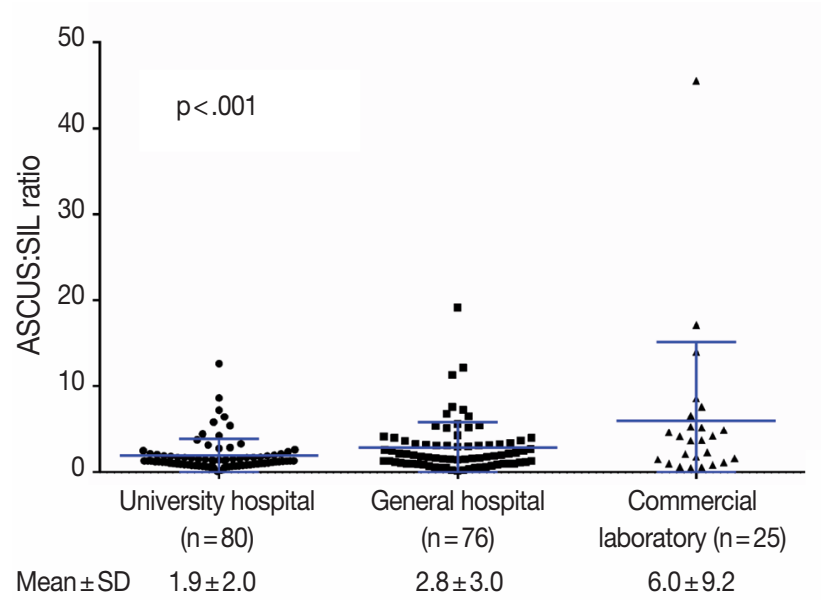

Fig. 6. Ratio of atypical squamous cells of undetermined significance (ASCUS) to squamous intraepithelial lesions (SIL) according to the type of medical institution in 2015.

\section{DISCUSSION}

The survey response rate for this study was quite high. In all, $99.0 \%$ of medical institutions providing cytopathology service responded to this survey as mandated by the QI program of the Korean Society for Cytopathology.

GYN cytology comprised $81.3 \%$ of all cases, which is due to the national cervical cancer screening program. Of the GYN cytology samples, $74.9 \%$ were examined at commercial laboratories, $13.9 \%$ at university hospitals, and $11.2 \%$ at general hospitals. In Korea, Pap smears are generally performed in primary care clinics and health promotion centers, and most of those specimens are then sent to commercial laboratories.

The conventional Pap smear is a simple and effective method for screening cervical cancer. LBC was initially introduced in GYN cytology, and its use has increased continuously over the past two decades. According to a previous nationwide study in Korea, the use of LBC comprised $7.6 \%$ and $20.5 \%$ of all cytology
Category O $\square$ Category A $\square$ Category B $\square$ Category C

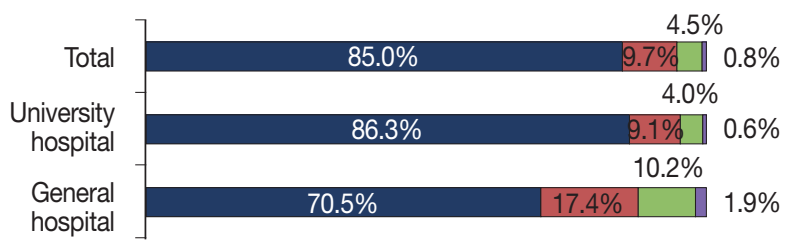

Fig. 7. Diagnostic accuracy of gynecologic cytology in 2015 according to the type of medical institution.

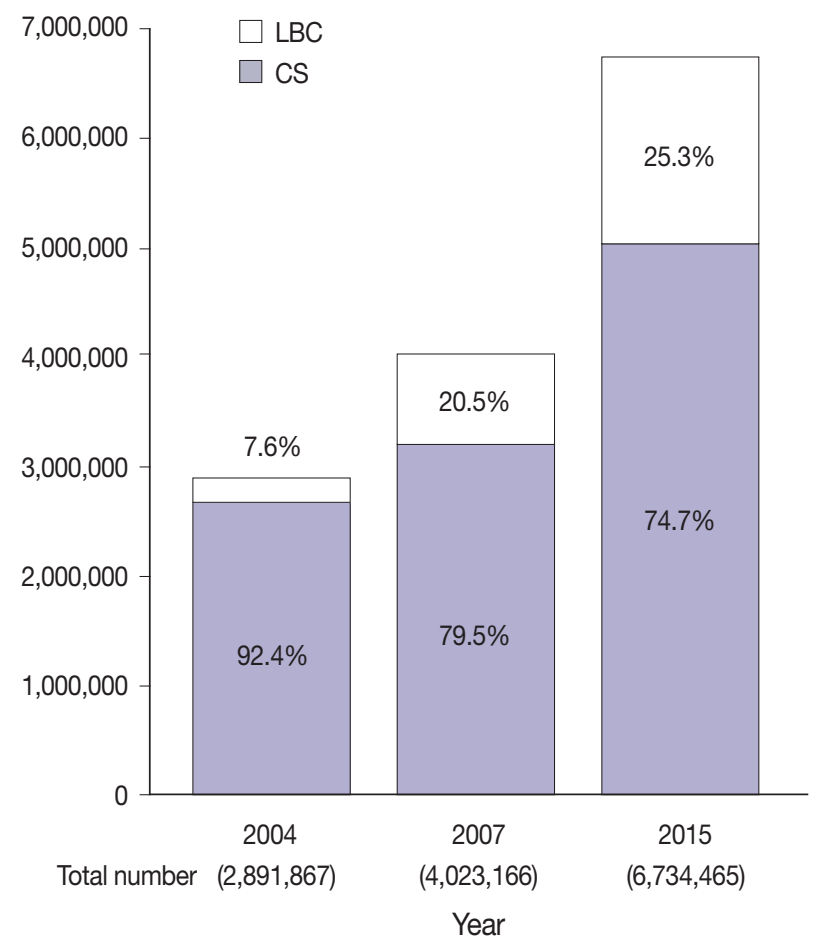

Fig. 8. Total number of gynecologic cytology cases according to the method of sample preparation at three different times. The number of cytology cases and the proportion of liquid-based cytology (LBC) have increased over time. CS, conventional smear.

cases in 2004 and 2007, respectively (Fig. 8). ${ }^{1}$ In 2015, LBC was used in $25.3 \%$ of all GYN cytology cases. In university hospitals, $55.9 \%$ of all GYN cytology were examined by LBC, whereas commercial laboratories used LBC less frequently (Fig. 2B).

In the field of non-GYN cytology, LBC is only used for body fluid and thyroid aspiration samples by the National Health Insurance System in Korea. The proportion of LBC in nonGYN cytology cases was higher in university hospitals than in other types of institutions (Figs. 3C, 4C). The thyroid gland was the highest source of FNA samples (Fig. 3B). The high number of thyroid FNA cases in Korea closely correlates with the high rate of thyroid cancer screening, as Korea has the highest incidence of thyroid cancer in the world. ${ }^{4}$ Although 11 methods of LBC 
were introduced in Korea, more than $95 \%$ of cases used either ThinPrep, Cell Prep, or SurePath. This is the first report to investigate the current status of the LBC methods used in Korea.

The overall rates of unsatisfactory, negative, and ASCUS for GYN cytology cases were $0.6 \%, 94.6 \%$, and $3.5 \%$ respectively. These results did not significantly differ among the three types of medical institutions. The ASCUS rate may have varied according to the cytopathologist performing the exam. The ASCUS:SIL ratio was less affected than the ASCUS rate by patient population, prevalence of disease, and the effect of screening. ${ }^{5-10}$ Thus, the ASCUS:SIL ratio was used as a quality control reference. ${ }^{10}$ In one study, cytotechnologists with an ASCUS:SIL ratio $<1.5$ showed a significantly lower sensitivity than those with a ratio $>3.0$. $^{5}$ In our study, the mean ASCUS:SIL ratio was 1.9 in university hospitals, 2.8 in general hospitals, and 6.0 in commercial laboratories (Fig. 6). Thus, the mean screening sensitivity of commercial laboratories may be higher when compared with referral hospitals.

Quality control of diagnostic accuracy was assessed by correlating cervical cytology with histologic results as mandated in university hospitals and general hospitals by the QI program of the Korean Society for Cytopathology. However, this correlation was not performed in most commercial laboratories. The concordance rate of cytologic and histologic diagnoses may vary depending upon the time difference between the two examinations. ${ }^{11-13}$ Diagnostic correlations between cytology and histology are lower when the two examinations are performed simultaneously than when cytology precedes histologic examination. ${ }^{11,12}$ During this study, we recognized that there was no standardization of cytologichistologic correlation methods, including the type of histologic specimens, the intervals for correlation, and the statistical metrics used. In our study, cytologic-histologic correlation was performed in real time and/or retrospectively. The tissue samples for histologic correlation were obtained from either cervical biopsy, conization, or hysterectomy.

We found that the volume of cytology cases, sample type, preparation method, access to paired tissue specimens, practice variables, and screening sensitivity all differed from institution to institution. In general, both the total volume of cytology cases and the proportion of cases using LBC have significantly increased. The screening sensitivity of GYN cytology was higher and more variable in commercial laboratories when compared with university and general hospitals. The results of this study can serve as basic data for the establishment of nationwide cytopathology policies and QI guidelines in Korean medical institutions.

\section{Conflicts of Interest}

No potential conflict of interest relevant to this article was reported.

\section{Acknowledgments}

This research was supported by The Korean Society for Cytopathology Grant No. 2015-02. The authors would like to acknowledge the Korean Society for Cytopathology and BD Korea for providing the funding necessary to carry out this study. We would also like to thank the Fellowship Council of the Korean Society for Cytopathology for its guidance in preparing and conducting this project and the Committee of Quality Improvement of the Korean Society for Cytopathology for providing the data.

\section{REFERENCES}

1. Lee HK, Kim SN, Khang SK, Kang CS, Yoon HK. Quality control program and its results of Korean Society for Cytopathologists. Korean J Cytopathol 2008; 19: 65-71.

2. Kim Y, Jun JK, Choi KS, Lee HY, Park EC. Overview of the National Cancer screening programme and the cancer screening status in Korea. Asian Pac J Cancer Prev 2011; 12: 725-30.

3. Min KJ, Lee YJ, Suh M, et al. The Korean guideline for cervical cancer screening. J Gynecol Oncol 2015; 26: 232-9.

4. Ahn HS, Kim HJ, Welch HG. Korea's thyroid-cancer "epidemic": screening and overdiagnosis. N Engl J Med 2014; 371: 1765-7.

5. Renshaw AA, Deschênes M, Auger M. ASC/SIL ratio for cytotechnologists: a surrogate marker of screening sensitivity. Am J Clin Pathol 2009; 131: 776-81.

6. Nascimento AF, Cibas ES. The ASC/SIL ratio for cytopathologists as a quality control measure: a follow-up study. Am J Clin Pathol 2007; 128: 653-6.

7. Juskevicius R, Zou KH, Cibas ES. An analysis of factors that influence the ASCUS/SIL ratio of pathologists. Am J Clin Pathol 2001; 116: $331-5$.

8. Davey DD, Naryshkin S, Nielsen ML, Kline TS. Atypical squamous cells of undetermined significance: interlaboratory comparison and quality assurance monitors. Diagn Cytopathol 1994; 11: 390-6.

9. Davey DD, Nielsen ML, Naryshkin S, Robb JA, Cohen T, Kline TS. Atypical squamous cells of undetermined significance: current laboratory practices of participants in the College of American Pathologists Interlaboratory: comparison program in cervicovaginal cytology. Arch Pathol Lab Med 1996; 120: 440-4.

10. Clary KM, Davey DD, Naryshkin S, et al. The role of monitoring 
interpretive rates, concordance between cytotechnologist and pathologist interpretations before sign-out, and turnaround time in gynecologic cytology quality assurance: findings from the College of American Pathologists Gynecologic Cytopathology Quality Consensus Conference working group 1. Arch Pathol Lab Med 2013; 137: 164-74.

11. Jones BA, Novis DA. Cervical biopsy-cytology correlation. A College of American Pathologists Q-Probes study of 22439 correlations in 348 laboratories. Arch Pathol Lab Med 1996; 120: 523-31.
12. Joste NE, Crum CP, Cibas ES. Cytologic/histologic correlation for quality control in cervicovaginal cytology: experience with 1,582 paired cases. Am J Clin Pathol 1995; 103: 32-4.

13. Crothers BA, Jones BA, Cahill LA, et al. Quality improvement opportunities in gynecologic cytologic-histologic correlations: findings from the College of American Pathologists Gynecologic Cytopathology Quality Consensus Conference working group 4. Arch Pathol Lab Med 2013; 137: 199-213. 